\section{Acción Poética: quando um estágio atravessa os muros da escola e impacta na população}

\author{
Acción Poética: when an \\ internship crosses the school \\ walls and impacts on the \\ population
}

Willian Henrique Cândido MOURA (PGET/UFSC) willianhenry_@hotmail.com

Naiane Carolina MENTA TRÊS (UFFS/PLE/UEM) willianhenry_@hotmail.com Eline Souza BARBOSA (UFFS) eline_sbf@hotmail.com

Recebido em: 30 de maio de 2018. Aceito em: 03 de out. de 2018.

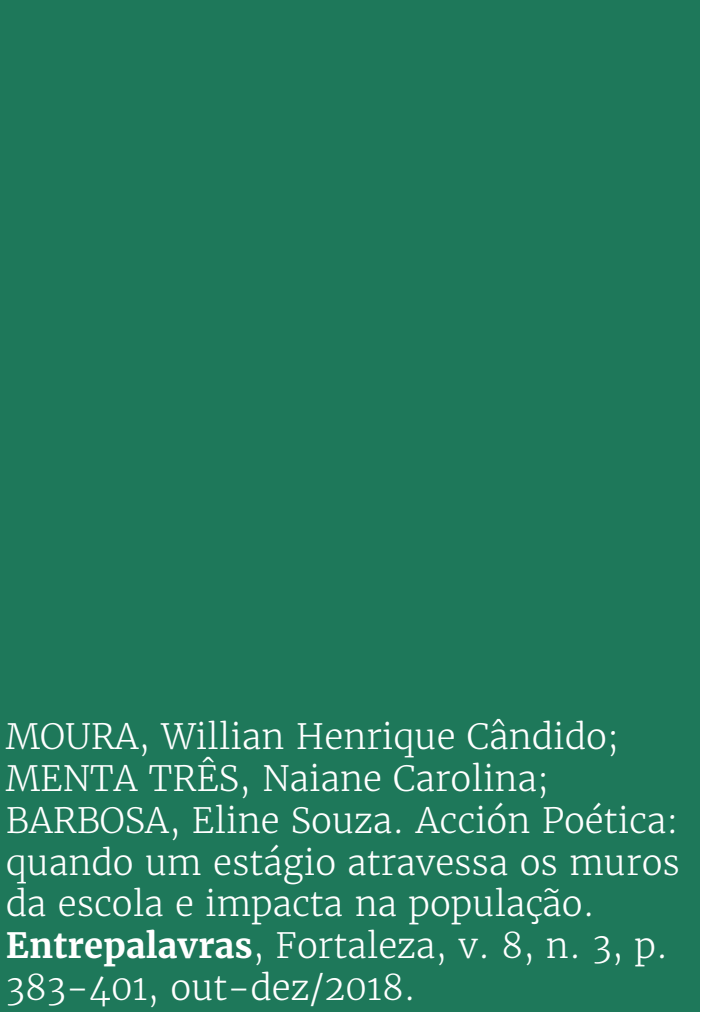

Resumo: O presente trabalho busca apresentar a prática de Estágio Curricular Supervisionado em Língua Espanhola V, realizada por dois acadêmicos do curso de licenciatura em Letras: Português e Espanhol da Universidade Federal da Fronteira Sul (UFFS), e como essa ação impactou na realidade da cidade. A prática de estágio foi desenvolvida com estudantes do Ensino Médio por meio de oficinas ofertadas no contraturno para os alunos que estudavam no período matutino. Nas oficinas de literatura contemporânea, com carga horária prática que extrapolou a obrigatória para esse estágio, apresentou-se o moderno e o contemporâneo na arte, enfatizando a literatura, a poesia, passando pela Antipoesía de Nicanor Parra até chegar no movimento Acción Poética, mostrando exemplos de práticas de poesias que foram feitas, especialmente, na América Latina, sempre analisando com os estudantes a estrutura do movimento e o que os poemas estavam significando. Na última oficina, os estagiários, a orientadora e os alunos realizaram práticas de Acción Poética em quatro muros da cidade, os quais foram previamente sondados pelos estagiários e solicitadas as devidas permissões para os responsáveis dos locais. Ao fim dessa 
v. $8(3)$

$383-401$

out-dez

2018

experiência, foi aplicado um questionário aos comerciantes de estabelecimentos próximos aos muros, para verificar o impacto que as pinturas causaram na cidade. Foi possível concluir que a Acción Poética pode e deve ser considerada uma metodologia de ensino e aprendizagem de língua espanhola e suas literaturas, assim como serve de formação leitora para pessoas que circulam pela cidade, fazendo com que o conhecimento escolar ultrapasse os limites curriculares.

Palavras-chave: Acción Poética. Literatura contemporânea. Prática de estágio de língua estrangeira.

Abstract: This paper aims to present the experience of the Supervised Internship in Spanish Language V, done by two undergraduate students of the course of Portuguese and Spanish Language and Literature of the Universidade Federal da Fronteira Sul (UFFS), and how that action had an impact on the city's reality. The practice of the internship was developed with High School students through workshops offered as an after-school activity for the morning students. At the contemporary literature workshops, with a workload that exceeded the limit for this internship, it was presented the modern and the contemporaneous on art, emphasizing literature, poetry, going through Nicanor Parra's Antipoesía until the so-called movement Acción Poética. Examples of poetical practices that were specially made in Latin America were showed, always analyzing with the students the movement foundation and what was the meaning of those poems. In the last workshop, the interns, their advisor, and the students made some Acción Poética interventions on four walls of the city, that had been previously prospect by the interns, and all the necessary permissions were requested. At the end of this experience, a questionnaire was given to the shops' owners who worked near the walls to verify the impact that the painting had caused the city. It was possible to conclude that Acción Poética can and should be considered a teaching methodology for the leaning of Spanish language and its literature, as it can be a reading formation for people who pass through the city making that school knowledge cross its curricular boundaries.

Keywords: Acción Poética. Contemporary literature. Foreign languages internship practice.

\section{Introdução}

O curso de Letras Português e Espanhol na Universidade Federal da Fronteira Sul (UFFS), campus Realeza-PR, possui em seu currículo cinco estágios de língua portuguesa e cinco estágios de língua espanhola. Organizados entre estágios que enfocam a língua ou a literatura, a última etapa do idioma estrangeiro, intitulada Estágio Curricular Supervisionado em Língua Espanhola V, deve ser um trabalho de literatura ${ }^{1}$ com alunos do Ensino Médio, como o exemplo descrito neste trabalho.

Este artigo apresentará a prática de estágio desenvolvida por meio de oficinas ofertadas no contraturno para os alunos que estudavam no período matutino. O estágio foi ministrado em dupla e teve uma carga

\footnotetext{
${ }^{1}$ Corroboramos com o que é abordado por Couto (2016) sobre a literatura nas aulas de Espanhol, a qual deve ser representada por meio de literaturas de Língua Espanhola, a fim de representar a amplitude de países e textos literários, dos mais diferentes gêneros, existente no universo hispânico.
} 
horária que extrapolou as 12 horas exigidas para o seu cumprimento. Isso se deve ao formato adotado para a prática de ensino, já que, em um desejo conjunto entre estagiários e orientadora de estágio, foi almejado trazer para sua realidade o movimento literário Acción Poética, projeto conhecido ao nível de América Latina por pintar poesias em muros cedidos pela população.

Uma das etapas obrigatórias ao final de cada estágio é o desenvolvimento de um relatório escrito, o qual possui um caráter funcional na reflexão do que foi apresentado pelos discentes. O presente trabalho objetiva ir além, pois deseja socializar o que foi planejado e executado no estágio, assim como analisar as consequências da atividade não apenas para os comumente envolvidos em um estágio de licenciatura - futuros professores e alunos - mas a repercussão da Acción Poética para os comerciantes da cidade. Os comerciantes convidados a responder o questionário representam o resultado da proposta encontrada pelos pesquisadores para investigar os desdobramentos gerados pela mediação de leitura utilizada.

A pesquisa se justifica por meio da importância da mediação de leitura nos dias atuais e na responsabilidade de universidades e escolas, através de estágios e projetos, atuarem juntas nessa tarefa.

'Promover a leitura' é uma ideia recente. Durante muito tempo, em diversos países, a preocupação estava mais voltada em saber quais os perigos que uma ampla difusão da leitura poderia trazer. (PETIT, 2001, p. 21, tradução nossa)².

A Acción Poética, mesmo com textos limitados pelo número de palavras, e nem sempre apresentando trechos de obras consagradas da literatura, representa uma exposição social da literatura contemporânea e faz com que as palavras cheguem a mais pessoas.

A descrição das etapas do estágio, juntamente com o proposto em cada uma das oficinas ofertadas, é parte integrante de Estágio: de quem é o protagonismo?, em uma tentativa de atentar para os envolvidos e suas funções para a realização das aulas. Em Da aprovação de um componente curricular à aprovação popular, o artigo contempla os desdobramentos que o estágio atingiu, apresentando os sujeitos que responderam à pesquisa e alguns acontecimentos e impressões que permearam o momento da realização da Acción Poética e a entrega dos questionários aos participantes. Os comerciantes de Realeza e a Acción Poética apresenta

2 "'Promover la lectura' es una idea reciente. Durante mucho tiempo, en numerosos países, la preocupación se orientó más bien hacia los peligros que podía traer una amplia difusión de la lectura." (PETIT, 2001, p. 21). 
v. $8(3)$

$383-401$

out-dez

2018

a análise das respostas dos participantes, comparando-as e fazendo um levantamento sobre os aspectos positivos e negativos apresentados nas respostas. Finalizando, em Considerações finais, está reforçada a necessidade de novas propostas para o ensino de leitura de literatura em língua espanhola, além das dificuldades encontradas para se concluir uma prática de ensino que ultrapasse os muros da escola e como essa prática atingiu de maneira positiva os objetivos propostos pelo estágio e pelo movimento Acción Poética.

\section{Estágio: de quem é o protagonismo?}

O presente artigo busca apresentar o trabalho desenvolvido na prática de Estágio Curricular Supervisionado em Língua Espanhola $\mathrm{V}$, realizado por uma dupla de estudantes da décima fase do curso de graduação em Letras: Português e Espanhol - Licenciatura, da Universidade Federal da Fronteira Sul (UFFS) do campus Realeza. O estágio em Língua Espanhola V é o estágio final de língua estrangeira e é uma etapa obrigatória no currículo do curso de Letras. O objetivo desse componente é que os acadêmicos consigam desenvolver suas regências, voltadas para o ensino de literatura no idioma, de forma a relacionar teoria e prática com alunos do Ensino Médio.

Para isso, os acadêmicos precisam desenvolver um projeto de estágio, seguido de planos de aula, regência e, posteriormente, um relatório reflexivo sobre sua trajetória ao longo da prática. Ao refletir sobre esse processo, nota-se o protagonismo dos estagiários, somado ao apoio dos professores orientadores e dos supervisores da escola. Porém, um estágio realmente preocupado com a formação de futuros professores e de uma experiência enriquecedora para seus alunos precisa transformar todos os envolvidos no processo em protagonistas.

Para uma melhor compreensão acerca dos envolvidos nesse processo, é importante apresentar aqui o local em que a prática foi desenvolvida. Todo o processo de estágio ocorreu no município de Realeza, localizado no sudoeste do estado do Paraná. Segundo dados do Instituto Brasileiro de Geografia e Estatística (IBGE, 2018), Realeza possuía uma população estimada em 17.111 habitantes no ano de 2017, ano em que aconteceu a prática de estágio aqui abordada. O estágio foi realizado no Colégio Estadual Doze de Novembro - Ensino Médio e Profissional, e se deu por meio de oficinas ofertadas no contraturno para os alunos que estudavam no período matutino. 
Ao iniciar o componente curricular de estágio, os acadêmicos necessitaram pensar em um tema para começar a desenvolver seu planejamento. Nessa prática, os estagiários resolveram partir de um desejo pessoal de inserir sua cidade em um projeto que abrange muitos países da América Latina: a Acción Poética.

Um projeto de pesquisa que nasce da decisão de um sujeito que, por interesse próprio ou de alguma entidade (órgão de desenvolvimento científico, universidade, secretarias municipais ou estaduais, outras instituições públicas ou privadas), resolve inferir na realidade, diagnosticando situações e buscando alternativas de ação. (AGUIAR, 2002, p. 128, tradução nossa)³.

Vislumbrando trazer a Acción Poética para a realidade de uma pequena cidade com pouco mais de 17 mil habitantes, os estagiários, ao se inserirem nesse movimento, fizeram do colégio uma escola aberta para o que acontece no mundo. Pensando nisso, o planejamento das aulas foi imprescindível para alcançar os objetivos propostos, tanto com as aulas de estágio, como com as pinturas do muro que vieram a modificar a paisagem urbana local.

A primeira etapa dessa prática consistiu em fazer uma sondagem na cidade a fim de identificar possíveis muros para que a Acción Poética fosse concretizada. Ao fim da sondagem, seis muros foram escolhidos para que se seguisse com a próxima etapa do movimento: solicitar as autorizações dos responsáveis para a pintura, pois, para praticar a Acción Poética, não é permitido realizar as pinturas em espaços que não foram cedidos para tal fim. Após esse contato com os responsáveis, dos seis muros solicitados, quatro tiveram permissão para serem poetizados. É importante destacar aqui que, segundo as características do movimento, as pessoas que cedem os muros passam a fazer parte da Acción Poética instantaneamente, pois também são sujeitos que estão envolvidos na ação.

Após definirem os muros, os estagiários iniciaram o processo de pintura com tinta branca pois, uma das marcas da Acción Poética é que os poemas sejam escritos em muros com fundo branco. Terminada essa etapa, devido às oficinas serem realizadas no contraturno, fora das aulas regulares dos alunos, foram realizados convites em todas as salas do colégio, visando atingir um maior número de participantes.

\footnotetext{
3 Un proyecto de investigación nace de la decisión de un sujeto que, por interés próprio o de alguna entidad (órgano de desarrollo científico, universidad, secretarías municipales o estatales, otras instituciones públicas o privadas), resuelve inferir en la realidad, diagnosticando situaciones y buscando alternativas de acción. (AGUIAR, 2002, p. 128).
} 
v. 8 (3)

$383-401$ out-dez 2018

Como o foco do estágio foi a literatura contemporânea, a primeira oficina, La poesía al revés: Antipoesía, teve como cerne a Antipoesía de Nicanor Parra. Para chegar a esse tema, os estagiários realizaram explicações a partir de uma progressão sobre a história da arte e da literatura até chegar à literatura contemporânea. Foi necessário fazer uma distinção entre o moderno e o contemporâneo na arte, em especial na literatura, para que os alunos pudessem olhar criticamente para a Antipoesía.

Após essa distinção entre o moderno e o contemporâneo na literatura, foram apresentados o escritor chileno Nicanor Parra e as características da Antipoesía, mostrados exemplos de antipoemas e artefatos, sempre analisando os modelos a partir das características do movimento e sua significação frente à compreensão dos alunos. Ao final dessa oficina, os alunos produziram antipoemas/artefatos a partir de materiais que os estagiários levaram para a sala de aula, como pode ser observado na Figura 1.

Figura 1 - "En el mundo moderno vamos a monetizar el cielo para vivir en el infierno"

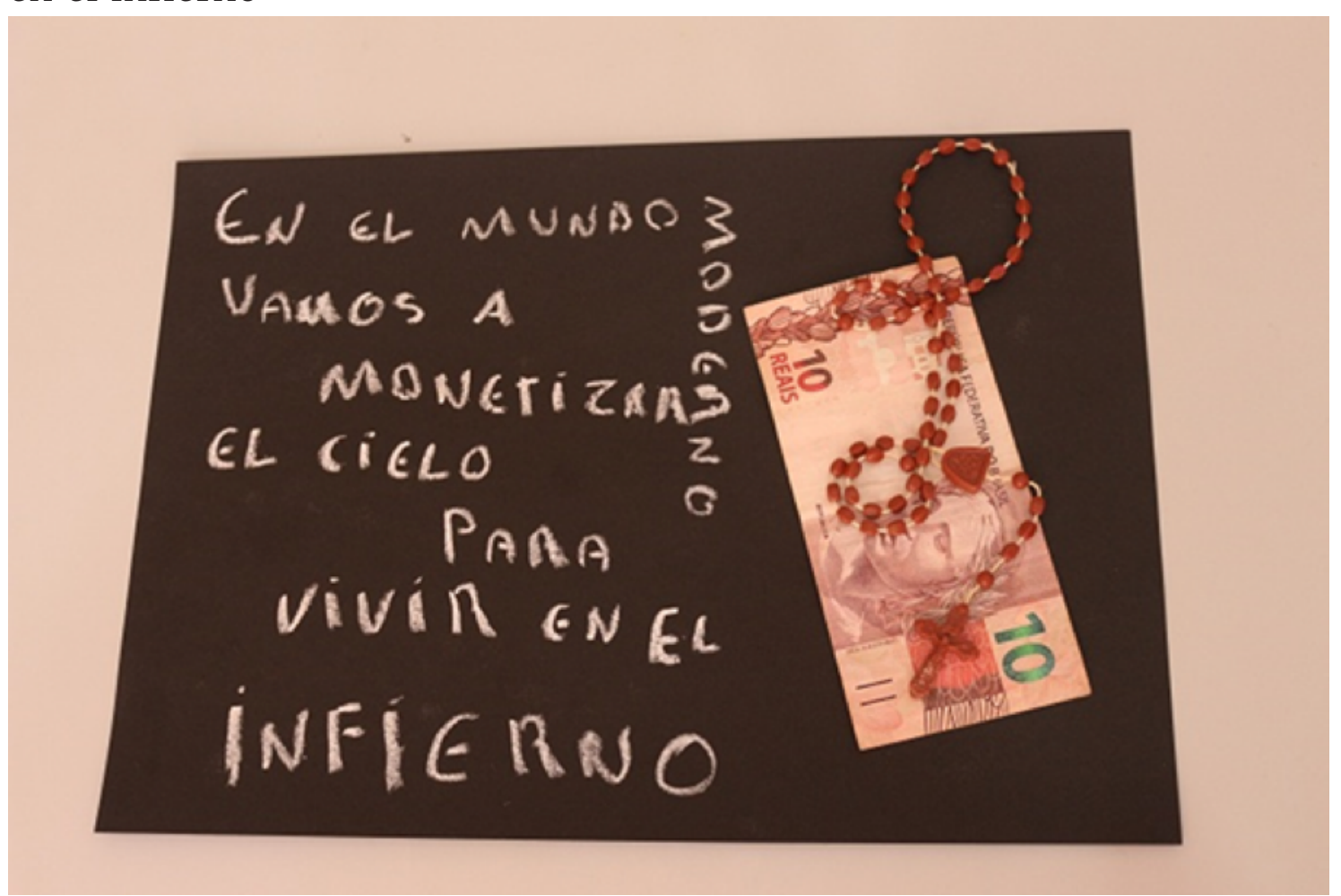

Fonte: Arquivo pessoal dos autores (2017).

No artefato apresentado, vemos uma cédula de dinheiro sob um rosário. Dois elementos tão diferentes e controversos entre si foram 
complementados pela antipoesía: "En el mundo moderno vamos a monetizar el cielo para vivir en el infierno". Ao serem analisados os artefatos produzidos, ficou nitidamente destacado que o objetivo com essa oficina foi alcançado, a Antipoesía fez significar no universo dos alunos. Como assegura Jouve (2002, p. 138):

[...] se a leitura tem um impacto no leitor, é porque ela relaciona o universo do sujeito com o do texto. O leitor, ao reagir positiva ou negativamente a essa experiência, sai dela inevitavelmente transformado.

Na segunda oficina, Soy un poeta urbano: conociendo la Acción Poética, a partir da retomada do que havia sido discutido na aula anterior, a literatura contemporânea e a Antipoesía, os estagiários deram seguimento com o tema desse encontro: a Acción Poética, movimento de literatura contemporânea que se iniciou na América Latina.

Desse modo, foram apresentados aos estudantes o escritor mexicano que deu origem ao movimento, Armando Alanís Pulido, e as características que fazem parte do movimento, tais como: a origem do muro, sua cor de fundo e o tamanho do poema escrito, que não pode ser muito extenso devido a seu principal objetivo, o de ser lido rapidamente pelas pessoas que passam pelo local. Além do mais, foi destacado para os alunos que os poemas pintados não podem ser de cunho religioso ou político.

Todas essas características estruturais do movimento foram analisadas a partir de exemplos de práticas de Acción Poética retiradas da internet. A circulação de imagens da Acción Poética na internet também é uma característica do movimento, pois ao final do processo, os participantes da ação tiram fotos e divulgam virtualmente seus feitos para que, por meio das fotografias e das tecnologias, mais pessoas no mundo possam ler e ter acesso aos poemas escritos e passem a conhecer o projeto. Segundo Menta Três e Mira (2018), as entrevistas com os participantes da Acción Poética Córdoba também utilizam a divulgação nas redes sociais para conhecer pessoas que queiram se envolver com o trabalho, solicitar novos muros e adquirir materiais de doação para as pinturas.

Após as análises, os estagiários e os estudantes partiram para o momento da seleção dos textos a serem poetizados nos muros. Cabe ressaltar aqui que o movimento prega que, antes dos poemas serem pintados, deve haver uma seleção conjunta por parte dos participantes. Os poemas vão desde frases de motivação, trechos e fragmentos de obras literárias, até frases de amor e reflexão. 
v. 8 (3)

$383-401$ out-dez 2018

Visando a dinâmica do projeto, os estagiários propiciaram aos alunos desenvolver uma maior autonomia no momento da escolha dos textos. Dispondo de livros de literatura em língua espanhola e alguns dicionários, estagiários e alunos iniciaram um processo de seleção dos textos para a Acción Poética. Ao final desse momento, várias ideias surgiram, e vários textos foram selecionados.

Em consenso, a equipe definiu que: um muro deveria ser pintado com um poema retirado do livro do idealizador da Acción Poética, Ritual del Susodicho (PULIDO, 2010), em outro muro deveria ser escrito um poema de criação própria, produzido entre alunos, estagiários e professora orientadora. Os outros dois muros deveriam ser completados com excertos de obras de literatura hispano-americana.

Definidos os textos a serem poetizados nos muros, a terceira oficina, Acción Poética: poesía en las calles, foi destinada para a prática de Acción Poética nos muros da cidade e teve como objetivo levar poesia contemporânea em língua espanhola para a cidade de Realeza. O protagonismo dos alunos, a partir de agora, passa a ser o foco da oficina e das pinturas no muro pois, para que ocorressem conforme o planejado, os alunos deveriam tomar iniciativas e se dedicar no momento da pintura.

Deste modo, seguiu-se a prática de Acción Poética em que, conjuntamente, alunos, estagiários e professora orientadora trouxeram poesia para as ruas da cidade. Ao final de cada pintura, conforme destacam Menta Três e Mira (2018), o movimento indica que deve ser realizada uma assinatura padrão: Acción Poética seguido do nome da cidade, nesse caso: Acción Poética Realeza. A fim de identificar a autoria do grupo foram criados dois stencils, um com o símbolo da UFFS e outro com o logo do colégio, os quais vinham somando a assinatura da Acción Poética Realeza. 
Figura 2: Poema de Armando Alanís Pulido modificado para a Acción Poética Realeza

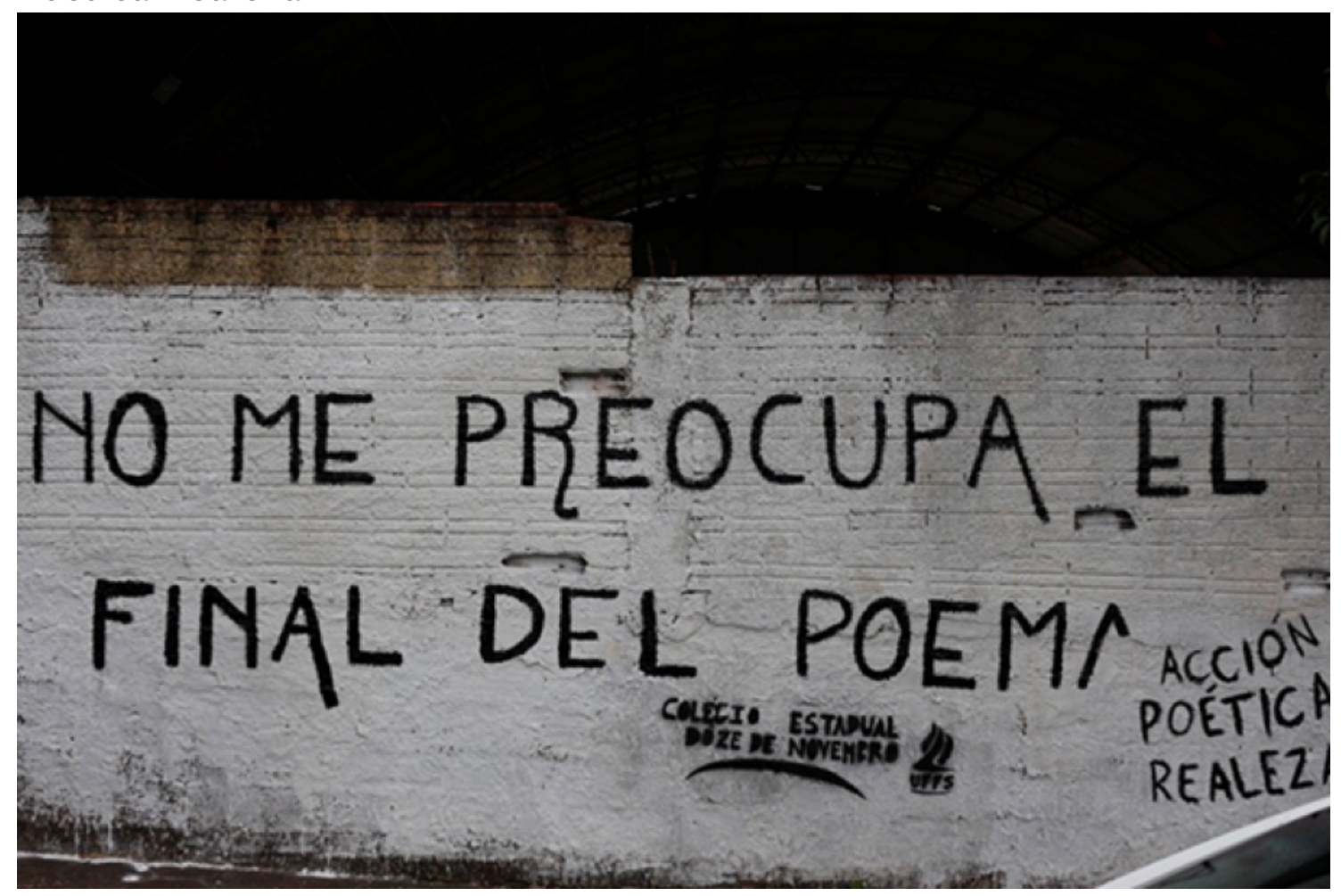

Fonte: Arquivo pessoal dos autores (2017).

Na Figura 2, encontra-se o excerto do poema retirado do livro de Pulido (2010), Ritual del Susodicho. Na Acción Poética Realeza, o poema No me preocupa el final del poema teve a letra A da palavra poema incompleta propositalmente para que fosse realizada uma brincadeira entre a letra incompleta e a interpretação do poema por parte dos leitores.

Dessa forma, corroborando com o que menciona Jouve (2002), a leitura literária é, mais do que qualquer outra, marcada subjetivamente. Por isso, cabe ao leitor do cotidiano realezense se deparar com essa marca na escrita do poema e fazer suas próprias interpretações, pois, como discute o autor, a leitura de literatura é enriquecedora no plano intelectual e potencializa o uso da imaginação. 
v. $8(3)$

$383-401$ out-dez 2018
Figura 3: ¿Cómo voy a creer que el horizonte es la frontera?

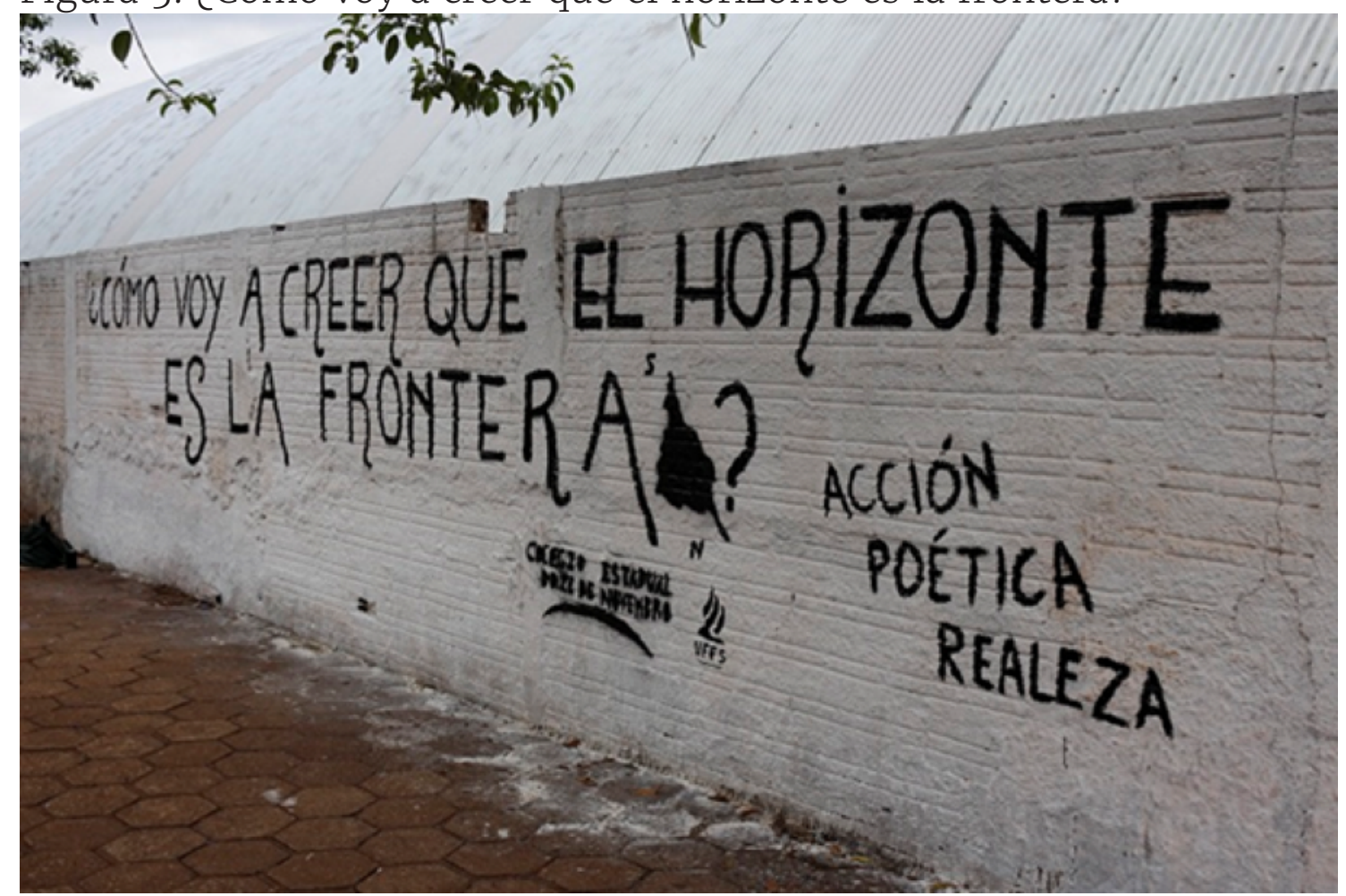

Fonte: Arquivo pessoal dos autores (2017).

A Acción Poética apresentada na Figura 3 é o excerto de um poema escrito por Mario Benedetti. A escolha desse excerto se justifica devido ao fato da cidade de Realeza se localizar em uma região de fronteira, estando a cerca de $60 \mathrm{~km}$ de distância da Argentina. Apesar da proximidade com o país vizinho, o colégio em que a prática foi desenvolvida não oferece a disciplina de Língua Espanhola para seus alunos na grade regular.

Sobre o ensino de espanhol no Brasil, de acordo com Silva e Pinto (2014, p. 13), "no ensino básico, o foco é na formação dos docentes e na inserção de conteúdos culturais da região do Mercosul". Partindo dessa informação, a representação da identidade de morador de fronteira foi reforçada ao ser escolhido tal poema. Além do mais, nessa Acción Poética, foi feita também uma alusão à obra América Invertida, do pintor uruguaio Joaquín Torres García, em que sul e norte invertem-se geograficamente como forma de representação ideológica.

Desse modo, implicitamente na pintura, o leitor que transitar pela frente do muro poderá se questionar sobre a pergunta que o próprio poema elabora e sobre o sentido na representação do mapa, posto ali de uma forma diferente da convencional. A partir disso, é trazido à tona o que 
Petit (1999, p. 62, tradução nossa)4 aborda: "a verdadeira democratização da leitura, é poder atingir a vontade, a totalidade da experiência da leitura em seus diferentes registros". Assim, ao somarem-se o poema em forma de questionamento e o mapa invertido, o leitor acabará por instigar-se criticamente, mesmo que involuntariamente, a respeito do sentido e do significado daquelas palavras em língua espanhola.

Figura 4: No hay muros que separen amores y poemas

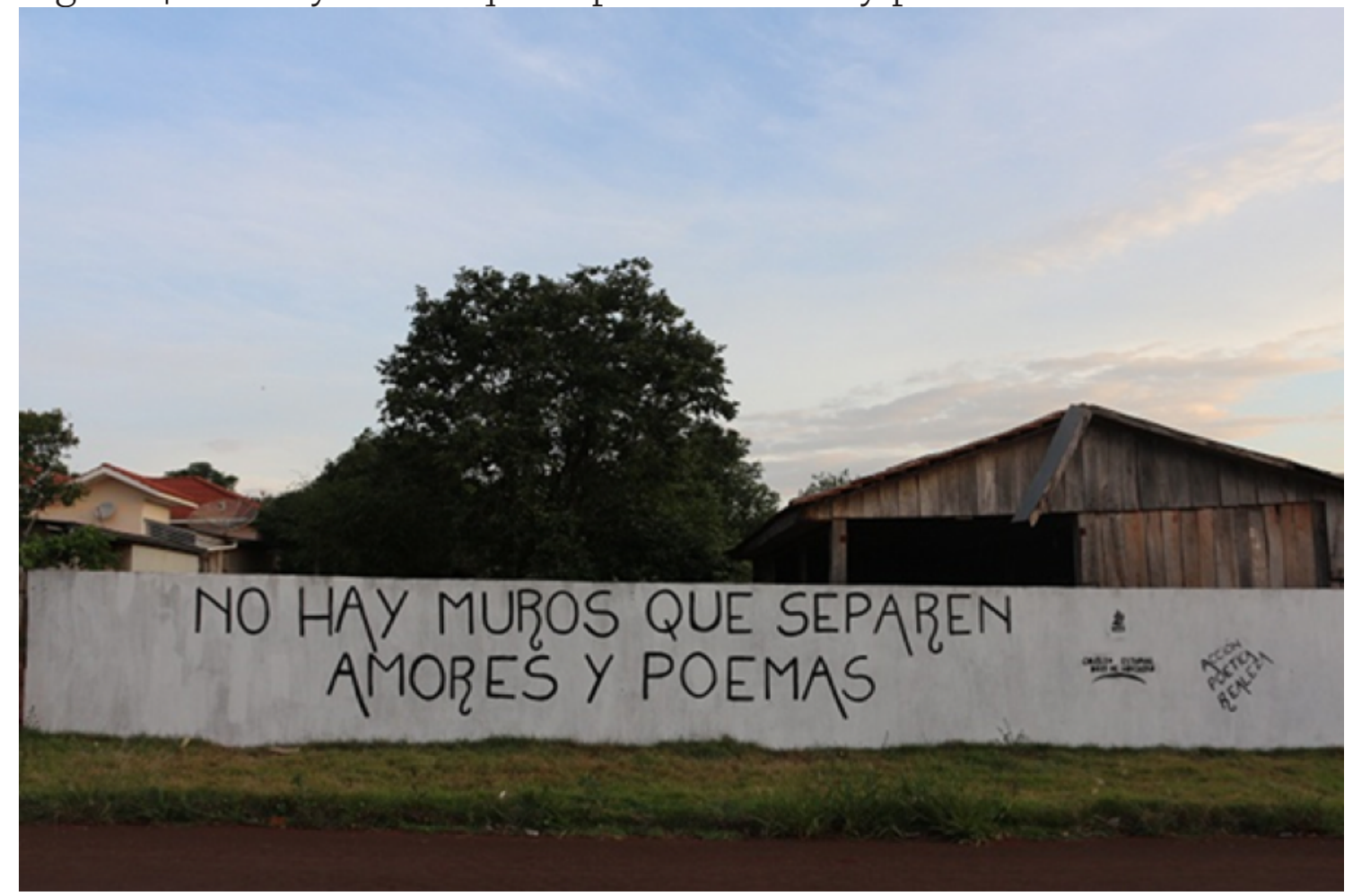

Fonte: Arquivo pessoal dos autores (2017).

O poema da Acción Poética representado na Figura 4 foi pintado no muro de uma residência particular e produzido em sala de aula, conjuntamente, pelos alunos, orientadora e estagiários. Sobre esse poema, é importante trazer o que discute Jouve (2002, p. 36): "pelos temas que aborda e pela linguagem que usa, cada texto desenha no vazio um leitor específico". A produção coletiva desse poema reflete o sentido poético motivacional, um dos tipos de textos expressos no movimento, para o leitor que se encontrar com a Acción Poética.

Sobretudo, o poema criado durante a oficina para a Acción Poética passa a ser literatura contemporânea. E se é literatura, é leitura. À vista disto, Zilberman (2012) expõe que a democratização da leitura

4 "La verdadera democratización de la lectura, es poder acceder a voluntad, a la totalidad de la experiencia de la lectura, en sus diferentes registros." (PETIT, 1999, p. 62). 
v. $8(3)$

$383-401$

out-dez

2018

passa por várias etapas, muitas delas nem sempre são praticáveis pela universidade ou pelo professor. Essas etapas dizem respeito a uma política cultural que permita o livro acessível, que habilite a população ao consumo de obras de arte.

Sendo assim, a Acción Poética passa a ser uma nova maneira de os alunos olharem para os textos literários, mais ainda, de fazerem parte da literatura e criarem gosto por ela. Desse modo, mesmo que dependa igualmente de uma decisão do professor - a de facultar a entrada da literatura em suas práticas de ensino, a literatura deve ser despida de segundas intenções em sala de aula, para que assim "talvez então as pessoas leiam ou produzam textos, sem constrangimentos e com grande gosto" (ZILBERMAN, 2012, p. 257) no próprio espaço da sala de aula, na cidade, no urbano. Como a Acción Poética, por exemplo, que talha paisagens de confronto para quem passa, um confronto poético com o leitor.

\section{Da aprovação de um componente curricular à aprovação popular}

O protagonismo dos alunos durante as aulas é fundamental para a aprendizagem. Professores na função de mediadores colaboram para que o ensino se desenvolva, principalmente ao se tratar de arte, já que a sensibilidade de cada um dos envolvidos é importante para resultar em um bom trabalho. Obviamente, o conhecimento gerado na escola deve ultrapassar seus limites físicos. Cada aluno carrega para sua vida as experiências de ensino que participou, porém o impacto social fica mais claro quando se trabalha com projetos que têm por objetivo sensibilizar a população.

A mediação de leitura realizada pelos estagiários foi uma proposta para que não apenas os alunos do Colégio Doze de Novembro vivenciassem o contato com a leitura literária em língua espanhola, mas que ambos fossem protagonistas em uma ação maior, a de mediar leitura para a população de Realeza. "Não é questão de fechar um leitor em uma gaveta, mas sim de oferecer-lhe pontes, ou melhor ainda, dar espaço para fabricar suas próprias pontes, suas próprias metáforas." (PETIT, 2001, p. 27, tradução nossa) ${ }^{5}$. Mesmo sem um grupo local específico como objeto de sensibilização através da leitura, os alunos aceitaram o desafio e se envolveram na atividade.

\footnotetext{
5 "Nunca es cuestión de encerrar a un lector en un casillero, sino más bien de lanzarle pasarelas, o mejor aún de darle ocasión de fabricar sus propias pasarelas, sus propias metáforas." (PETIT, 2001, p. 27).
} 
Destaca-se que durante a pintura dos muros, muitos transeuntes se aproximaram dos muros e pediram informações sobre o projeto, outros tiraram fotos, fizeram comentários e elogiaram o trabalho que estava sendo desenvolvido. O que demonstra que, apesar de ser uma atividade de cunho escolar, chamou a atenção das pessoas que passavam, pois a pintura não estava ocorrendo apenas nos muros das escolas, como geralmente são as atividades de pintura dos alunos.

A partir dos comentários surgidos no dia da Acción Poética, refletiuse que era necessário avaliar o impacto dessa mediação. Sendo assim, utilizouse de um questionário e foi realizado o convite para que comerciantes com estabelecimentos próximos aos muros pintados participassem da pesquisa. Os sujeitos dessa pesquisa foram selecionados por acreditar-se que os comércios possuem circulação de pessoas e que possíveis comentários poderiam surgir entre clientes e proprietários, diante da Acción Poética.

Dos quatro muros escolhidos, três estavam localizados no centro da cidade e pertenciam a órgãos públicos: dois delimitavam o colégio em que se realizou a prática, estando sob a responsabilidade da direção do colégio, e o outro fazia parte de um parque infantil e esportivo municipal, de responsabilidade da prefeitura do município. O quarto muro era de uma residência privada e situava-se em um bairro periférico, numa rua de grande fluxo de automóveis e pessoas para chegar a vários bairros residenciais e à UFFS.

Ao redor desses três muros haviam sete comércios: três lojas de roupas, uma loja de brinquedos e papelaria, um bar e mercearia, uma loja de doces e uma banca de jornais e revistas. Todos os comércios receberam um questionário padrão e foram convidados a participar da pesquisa. Contudo, somente 4 comerciantes entregaram o questionário respondido no ato do recolhimento. Foram denominados da seguinte forma: C1, C2, C3 e C4. A letra "C" refere-se a comerciante e os números que a acompanham foram utilizados para distinção de cada membro. Esse procedimento foi tomado para não expor a identidade de nenhum participante da pesquisa.

Os participantes eram homens e mulheres e suas idades variavam entre 30 e 65 anos. Uma comerciante se negou a responder à pesquisa, e comentou que seus clientes a questionavam sobre o significado dos escritos, se era algo obsceno ou ofensivo e que quem havia feito aquela "pichação" nos muros deveria ser preso. A participante indicou que era necessária uma tradução para um melhor entendimento da Acción Poética, pois ela mesma não sabia o significado. 
v. $8(3)$

$383-401$

out-dez

2018

No ato da entrega do questionário, um casal de comerciantes, afirmou que não havia compreendido os escritos do muro, que queriam mais informação para poderem entender e conversar sobre o tema com seus clientes. Questionaram várias vezes quem era a Acción Poética, e que estavam imaginando que isso era alguma intervenção comunista. Como resposta, foi solicitado que esses participantes colocassem tudo isso no questionário, suas dúvidas e inferências, que serão abordadas na sequência.

\section{Os comerciantes de Realeza e a Acción Poética}

A presente pesquisa, além de relatar e refletir sobre o estágio realizado, objetivou analisar a relação entre a Acción Poética Realeza e os participantes envolvidos por meio de questionários. Consideram-se como participantes envolvidos, os alunos participantes do projeto, as pessoas que cederam os muros para pintura e a população da cidade de maneira geral. No caso deste artigo, optou-se pela análise do questionário proposto aos comerciantes, que refletem o impacto na cidade, já que o material coletado com os alunos e os donos dos muros são fruto de outras pesquisas desenvolvidas.

Ao serem questionados se já conheciam ou tiveram algum contato com a Acción Poética antes da pintura do muro localizado próximo ao seu estabelecimento, os sujeitos da pesquisa negaram. Para C1, "Antes da pintura do muro não tínhamos conhecimento sobre o artista, mas acho interessante o que fizeram, assim acaba passando um pouco de cultura à população". Quando se refere ao artista, C1 fala de Armando Alanís Pulido, idealizador do projeto que se espalhou para os muros do mundo. A informação tornou-se conhecimento de $\mathrm{C} 1$ por meio de conversa desenvolvida com os pesquisadores.

Destaca-se também a resposta de C2: "Não conhecia, e não sabemos o significado, gostaríamos de saber o significado". A partir dessa resposta, pode-se notar que $\mathrm{C} 2$ não possui conhecimento da língua espanhola e gostaria de entender o que a frase quer dizer. Com base nas respostas apresentadas, nota-se que existe o interesse, por parte da população, de saber mais sobre o projeto e os escritos.

A segunda pergunta do questionário foi: "Qual a importância de realizar a Acción Poética em Realeza?". Segundo C1, "Assim passa uma mensagem importante à população e aos que leem, e a cultura é importante na sociedade". A ideia de enriquecimento cultural também foi abordada na resposta de $\mathrm{C} 4$ e compactua com o pensamento de leitura literária defendido por Petit: 
[...] a leitura, e mais precisamente a leitura literária, nos introduzem em um tempo próprio, no qual a fantasia tem liberdade e permite imaginar outras possibilidades, protegendo-nos da agitação cotidiana. (PETIT, 2001, p. 51, tradução nossa) $)^{6}$.

Apesar de não justificar a resposta, C3 afirmou que foi interessante que a atividade da pintura tenha sido realizada em língua espanhola. Faz-se necessário lembrar que Realeza, como descrito ao longo deste artigo, está localizada na faixa de fronteira entre o Brasil e a Argentina. A resposta de C3 é uma forma de reconhecimento à integração comercial, cultural e social existente com o país vizinho, apesar da limitação da língua existente, o que comprova a importância de ter sido inserido o curso de Letras: Português e Espanhol na UFFS para a região.

A questão 3 destinava-se a descobrir sobre a repercussão de cada muro no ambiente comercial, entre clientes e proprietários. C1 comentou que "Despertou curiosidade sobre a frase, assim saber o que a mensagem passava, o que dizia, muitas pessoas paravam para ler e entender sobre as frases." Isso porque "[...] o leitor não consome um texto passivamente; se apropria, o interpreta, modifica seu sentido, liberta sua fantasia, seu desejo e suas angústias" (PETIT, 2001, p. 28, tradução nossa) ${ }^{7}$.

Para C2, "Sim, houve bastante questionamento, mas ninguém chegou a uma conclusão." A resposta de C2 pode ser complementada pela repercussão que os muros ganharam em uma página da internet destinada a fazer humor com os acontecimentos da cidade, já que, por desconhecimento, muitas pessoas relacionaram a atividade com pichação, ato considerado de vandalismo e sem permissão de pintura no local. Apesar de apresentar identificação da Acción Poética, do colégio envolvido e da UFFS, a página se referiu com humor a uma possível pichação realizada por argentinos, destacando a rivalidade também existente na região de fronteira. Assim, pode-se relacionar aos questionamentos citados por $\mathrm{C} 2$, já que a população entendeu que se tratava de uma ação educativa, mas ao mesmo tempo foi relacionada ao mais próximo do que era de seu conhecimento, a pichação.

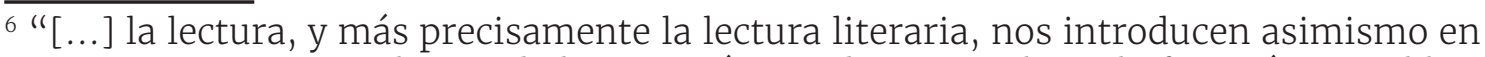
un tiempo propio, a cubierto de la agitación cotidiana, en el que la fantasía tiene libre curso y permite imaginar otras posibilidades." (PETIT, 2001, p. 51).

7 "[...] el lector no consume pasivamente un texto; se lo apropia, lo interpreta, modifica su sentido, desliza su fantasía, su deseo y sus angustias." (PETIT, 2001, p. 28).
} 
v. $8(3)$

$383-401$

out-dez

2018

Sobre a pergunta 3, C4 declarou que "Sim, houve espanto e admiração por ser algo inusitado, diferente". O uso das palavras "espanto" e "admiração" merece destaque, pois demonstra quehouve certo estranhamento por parte da população que entrou em contato com C4. Há uma progressão na resposta de C4: inicialmente a população se espantou; em seguida passaram a admirar a Acción Poética, o que passa a ser complementado quando diz que foi algo "inusitado, diferente", ou seja, algo que chegou de repente como uma surpresa para a paisagem urbana. Dessa forma, pode-se reafirmar o que discute Jouve (2002, p. 139), "os textos mais enriquecedores são aqueles que, ao confrontarem o leitor com a diferença, permitem-lhe se descobrir outro". C3 apenas relatou ter ouvido opiniões positivas sobre a Acción Poética em Realeza, não se atendo a detalhes ou informações adicionais.

Quando questionados sobre suas próprias opiniões com relação ao projeto, $\mathrm{C} 1$ afirmou:

Achei interessante sobre o que fizeram assim todos puderam conhecer sobre o artista e sobre a frase, a mensagem que passava. Apesar de que acho que muitas pessoas não sabem o que diz a mensagem (risos).

Novamente existe uma marca nas respostas que revela o desconhecimento da população perante a língua espanhola. Os risos, escritos entre parênteses, podem ser interpretados como uma resposta a uma literatura que está disponível para todos da cidade, sem a necessidade de buscar livros em bibliotecas ou pela intervenção de um professor em sala de aula, e que mesmo assim pode estar distante dos leitores, limitados pela língua.

Conforme Jouve (2002, p. 22):

[...] toda leitura interage com a cultura e os esquemas dominantes de meio e de uma época. A leitura afirma sua dimensão simbólica agindo nos modelos do imaginário coletivo quer os recuse quer os aceite [...].

Ou seja, no momento em que a população da cidade passa a ler os textos nos muros, estão interagindo com a leitura literária e, por consequência, com a língua espanhola, visando que Realeza se localiza numa região de fronteira e que nesse local os cidadãos falam português.

O limite também se encontra no formato da mediação de leitura desenvolvida pela Acción Poética. C2 diz que "Gostaria de saber mais sobre a Acción Poética, tenho dúvidas e para poder ajudar a quem 
me pedir o que é." Notou-se que os relatos de pouco conhecimento sobre o projeto são recorrentes, e que C2 se sente responsável por saber o que representa para poder repassar aos seus clientes que também possuem dúvidas. Porém, nota-se que a curiosidade não despertou o desejo de $\mathrm{C} 2$ em buscar mais informações sobre o projeto, que poderia ser facilmente encontrado na internet. O que talvez possa demonstrar dois aspectos, o primeiro é que a falta de conhecimento do projeto é tanta que limitou a busca, ocorrendo apenas quando os pesquisadores entraram em contato. Outra opção seria que, apesar da mediação de leitura por meio da Acción Poética funcionar, a falha pode estar na falta de sequência do leitor.

Assim como C3, todos os participantes da pesquisa acharam pessoalmente a experiência positiva. Para C4, outras ações como esta deveriam ser realizadas. Mesmo com uma amostra pequena de pesquisa, acredita-se que ter realizado a entrevista com os comerciantes instalados próximos aos muros pintados foi a melhor opção para captar parte do resultado gerado pelo estágio que vai além dos muros da escola. Isso porque acredita-se que um estágio, independente da licenciatura, não deve focar apenas na realização exitosa de um componente, mas no impacto social que pode causar. Avaliado nesse caso com repercussão positiva, mesmo que os poemas oferecidos pela Acción Poética não tenham sido totalmente compreendidos pela população, pois assim é a arte.

\section{Considerações finais}

O Estágio Curricular Supervisionado em Língua Espanhola V possibilitou não só a oportunidade de trabalhar com um movimento de poesia que está crescendo na América Latina, como também trazer para a cidade de Realeza um pouco desse movimento que possibilita uma mudança na imagem da cidade e na vida das pessoas que circulam pelas ruas, uma vez que os poemas nos muros foram pensados e escritos para serem objetos de transformação cotidiana.

A experiência do estágio aqui relatado foi enriquecedora. Acadêmicos, professora orientadora, alunos da escola e a comunidade de Realeza participaram do processo acadêmico, mas também literário e social. A atividade exigiu dos envolvidos mais tempo do que o previsto nos documentos que regulamentam o estágio na UFFS, porém demonstrou que o movimento Acción Poética pode e deve ser trabalhado como uma metodologia de ensino e aprendizagem da Língua Espanhola. 
v. $8(3)$

$383-401$

out-dez

2018

Além disso, através dos relatos dos comerciantes, foi possível verificar que os muros pintados chamaram a atenção da população e existiu uma movimentação de leitores que buscavam entender o significado dos textos literários em língua espanhola, obtendo êxito a partir dos objetivos propostos com o estágio e com a Acción Poética. Segundo Petit:

Para quem vive em bairros pobres, nas periferias das cidades, ou no campo, os livros são objetos raros, pouco familiares, investidos de poder, que dão medo. Estão separados dessas pessoas por verdadeiras fronteiras, visíveis ou invisíveis. E se os livros não vão até eles, eles nunca irão até os livros. (PETIT, 2001, p. 24, tradução nossa) ${ }^{8}$.

Por isso, destacamos que a mediação leitora através da Acción Poética, em língua espanhola, em uma cidade da região de fronteira entre o Brasil e a Argentina, possui um caráter formativo, não apenas de leitores, mas de cidadãos críticos e sensibilizados com outras culturas e outras línguas.

Por meio dos questionários identificou-se que, como outras artes, a literatura inquieta, e expô-la nos muros da cidade resultou em espanto e admiração. De modo geral, os participantes da pesquisa declararam-se a favor do movimento e ressaltaram o aspecto cultural que a atividade trouxe para a cidade. Ouvir os comerciantes da cidade foi uma ação de apropriação das reações geradas pela mediação, mas existe o desejo da sequência da investigação, com base no material já coletado com os alunos da escola e com os responsáveis pelos muros que foram cedidos para as pinturas. Acredita-se que essas pesquisas serão complementares ao exercício realizado neste artigo.

Mesmo com as dificuldades e obstáculos encontrados ao longo de todo o percurso do estágio, tais como o tempo gasto com a procura dos muros e solicitar suas autorizações para realizar a Acción Poética, e o dinheiro gasto com a compra dos materiais de pintura, acredita-se que realizou-se uma aproximação entre literatura contemporânea e a leitura literária em língua espanhola para com as pessoas que circulam pela cidade, fazendo com que o conhecimento escolar extrapolasse os limites curriculares e, mais ainda, os muros da escola.

\footnotetext{
8 "Para quienes viven en barrios pobres en las orillas de las ciudades, o en el campo, los libros son objetos raros, poco familiares, investidos de poder, que dan miedo. Está separados de ellos por verdaderas fronteras, visibles o invisibles. Y si los libros no van a ellos, ellos nunca irán a los libros." (PETIT, 2001, p. 24).
} 


\section{Referências}

AGUIAR, V. T. Como planificar la investigación en el área de la lectura. p. 127-133. In: RÖSING, T. M. K. Leitura e animação cultural: repensando a escola e a biblioteca. Passo Fundo, RS: Editora da UPF, 2002.

COUTO, L. P. Didática da Língua Espanhola no Ensino Médio. São Paulo, SP: Cortez, 2016.

INSTITUTO BRASILEIRO DE GEOGRAFIA E ESTATÍSTICA. Realeza. Disponível em: <https://cidades.ibge.gov.br/brasil/pr/realeza/ panorama> Acesso em: 26 maio 2018.

JOUVE, V. A leitura. São Paulo: UNESP, 2002.

MENTA TRÊS, N. C.; MIRA, E. Los productores de la Acción poética Córdoba como animadores de lectura. In: Memorias del Congreso Internacional Lectura 2018: Para leer el XXI Se ha de conocer las fuerzas del mundo para ponerlas a trabajar [CD-ROM]. La Habana, 2018.

PETIT, M. Nuevos acercamientos a los jóvenes y la lectura. México, DF: Fondo de Cultura Económica, 1999.

Lecturas: del espacio íntimo al espacio público. México, DF: Fondo de Cultura Económica, 2001.

PULIDO, A. A. Ritual del Susodicho/Ritual do dito cujo. Tradução de

Rafael Rocha Daud. Monterrey, Mx: Mantis Editores, 2010. Edição bilíngue.

SILVA, M. R.; PINTO, A. C. T. Fronteira e educação: de que lado estamos? In: PINTO, A. C. T.; SILVA, M. R. (Orgs.). De frente para a fronteira: reflexões sobre educação em área de fronteira. Chapecó, SC: Universidade Federal da Fronteira Sul, 2014.

ZILBERMAN, R. A leitura e o ensino da literatura. Curitiba, PR: InterSaberes, 2012. 